\title{
A FORMAÇÃO PROFISSIONAL DO LICENCIADO EM PEDAGOGIA DO SETOR DE EDUCAÇÃO DA UFPR
}

\author{
COLEGIADO DO CURSO DE PEDAGOGIA
}

\section{0 - ANTECEDENTES}

A preocupação com a formação de professores se fez presente no Setor de Educação desde a sua criação. As discussões iniciadas a partir do ano de 1971 se tornaram mais efetivas em $1979 \mathrm{com}$ a significativa participação de professores e alunos, quando foram desenvolvidos trabalhos com o intuito de caracterizar a identidade e o papel do Setor de Educação na Universidade.

Em 1981, novos estudos se efetivaram, gerando uma proposta (Educar, v. 2, n. 1, p. 165) que tomou corpo, respondendo as solicitações originárias do MEC com vistas à Reformulação dos Cursos de Recursos Humanos para a Educação.

No presente momento tenta-se uma retomada dos estudos anteriores, bem como um novo posicionamento onde o foco central passa a ser a FORMAÇÃO DO PROFESSOR.

\section{$2.0-$ PRESSUPOSTOS}

As idéias a seguir constituem-se em pontos preliminares, ordenadores de discussão.

2.1 - Reafirma-se a necessidade da existência de um Setor que abrigue e concentre o Curso de Pedagogia e a formação pedagógica dos cursos de licenciatura. 
2.2 - A Pedagogia e a Licenciatura devem ser focalizadas de um ponto de vista único - o da formação do professor. Com isso, a Pedagogia passa a ser considerada uma Licenciatura no sentido de se fortalecer a formação do magistério de $2 .^{\circ}$ grau, sem prejuízo da formação nas diferentes habilitações.

Estabelece-se como idéia principal que a busca de alternativas para a formação do professor se fará de forma conjunta: áreas de conhecimento específico (Licenciaturas) e Setor de Educação.

2.3 - Privilegia-se a idéia de que professor e educador são conceitos indissociáveis, visto que na formação do primeiro está implícita a do segundo.

2.4 - Dá-se ênfase à valorização das Licenciaturas em todas as áreas, acentuando-se que o conteúdo pedagógico deve se fazer presente de forma integrada e globalizada na FORMAÇÃO DO PROFESSOR.

2.5 - As proposições contidas no Documento do Setor de Educação/81 merecem ser repensadas e/ou aprofundadas.

2.6 - A ênfase na realidade brasileira, na qual se inscreve a educação, não se deve constituir apenas em ponto de partida, mas eixo comum na formação do profissional em educação.

\section{0 - PRINCÍPIOS BÁSICOS PARA A FORMAÇÃO DO PROFISSIONAL EM EDUCAÇÃO}

3.1 - Quanto à concepção de educação:

- a abordagem dos problemas de formação pedagógica pressupõe uma análise mais ampla da educação no contexto social;

- a educação não é um processo isolado, mas uma variável do processo histórico-cultural, que tem sua especificidade; 
- esta especificidade é inerente às formas de produção e veiculação do saber: criação, transmissão e valorização deste saber a nível dos indivíduos e dos grupos sociais; trata-se, portanto, de um saber situado no tempo social e histórico;

- a educação como uma ação intencional ocorre em situações formais e não-formais, que evidenciam diferentes necessidades, incluindo 0 atendimento mesmo daqueles que não estão na escola;

- estas situações requerem agentes educacionais - escolas e profissionais - capacitados ao enfrentamento dos problemas e necessidades da realidade educacional brasileira.

3.2 - Quanto à formação do profissional em educação:

- a formação do professor necessariamente incluirá a formação do educador;

- é neste sentido, que o professor pode ser considerado como o profissional que domina conteúdos específicos, as formas de tratamento deste conteúdo e as relações existentes entre tais conteúdos e formas, com a totalidade das relações educacionais, sociais, econômicas, políticas e culturais;

- os problemas da formação do professor, portanto, só podem ser resolvidos quando o Curso de Licenciatura for entendido como um todo, pois, restringir a formação do professor ao domínio dos conteúdos a serem ensinados ou ao tratamento visando à reprodução de modelos pedagógicos implica uma visão fragmentada do profissional da educação;

- caberão a este profissional diferentes formas de atuação, onde não só a educação escolar regular seja privilegiada, "daí a importância da educação extra-escolar..., com o intuito de efetivar a idéia de uma educação ao longo da vida e voltada para 
uma maioria da população e de segmentos populacionais, com crianças na faixa etária de 0 a 6 anos, adultos em serviço ou na $3 .{ }^{a}$ idade, segregados sociais, etc." (Doc. 81, p. 168).

\section{0 - TIPO DE CURSO DE FORMAÇÃO DO PROFISSIONAL EM EDUCAÇÃO}

4.1 - Estes dois aspectos da formação profissional do professor podem situar-se em dois planos: um referente ao processo e ao resultado dos estudos gerais por ele realizados num domínio particular da atividade humana (formação profissional específica) e outro referente tanto ao conjunto de processos que levam o professor a exercer a atividade docente quanto ao produto desse conjunto de processos (formação pedagógica).

4.2 - O domínio do conteúdo do campo particular do conhecimento a que um curso de Licenciatura está vinculado é fundamental para que o professor não atue como um reprodutor de matérias de ensino, mas que sintetizando com originalidade os conteúdos em sua forma de abordagem, possibilite ao alunos uma nova visão da realidade.

4.3 - A formação pedagógica como forma de desenvolvimento de competências específicas e de instrumentalização para o ensino, implicará uma fundamentação sobre a educação que se concretiza, na aquisição de conhecimentos mediante o estudo das Ciências da Educação e a sua aplicação na solução das questões do ensino, sem perder de vista a problematização do real.

4.4 - O conhecimento da problemática educacional brasileira é imprescindível na formação do professor.

4.5 - As disciplinas pedagógicas devem ser desenvolvi- 
das integradamente entre si e com as disciplinas do campo particular do conhecimento, tendo em vista a formação do professor no seu todo. Essa integração implicaria:

- trabalho integrado entre professores das várias disciplinas do curso;

- participação ativa dos representantes do Setor nos Colegiados dos Cursos de Licenciatura;

- recriação da Coordenação das Licenciaturas.

4.6 - A Prática de Ensino deverá ser desenvolvida desde o início do curso, de forma a possibilitar a ampliação da experiência do aluno em situações reais de ensino, mediante diferentes alternativas de estágio.

\section{0 - PROPOSTA}

5.1 - Quanto à formação para a Licenciatura e as Habilitações em Pedagogia:

- O profissional a ser formado pelo Curso de Pedagogia caracteriza-se:

a) Como professor licenciado para atuar quer no $2 .^{\circ}$ grau, quer nas séries iniciais do $1 .^{\circ}$ grau. Enfatiza-se a importância de que a formação para ambas as áreas se dê simultaneamente.

b) Concomitantemente, a nível de graduação, como habilitado em área de sua opção. Ficam definidas como áreas as seguintes habilitações: Orientação Educacional, Supervisão Escolar, Administração Escolar, Pré-Escolar e Magistério em Educação Especial.

- Propõe-se a integração das habilitações técnico- 
administrativas através da estruturação de um bloco de disciplinas comuns.

- Sugere-se como recomendações adicionais: Inclusão na forma de conteúdos e/ou disciplinas dos temas: educação extra-escolar, educação no meio rural, educação de adultos, educação popular e alfabetização.

Que se dê ênfase ao estudo de autores e obras que compõem o pensamento pedagógico brasileiro.

A seguir, constam a Resolução n. ${ }^{\circ}$ 02/85-CEP, o plano de estudos e o ementário de disciplinas obrigatórias do Curso de Pedagogia. 


\section{ANEXOS}

Resolução n. ${ }^{\circ}$ 02/85-CEP: estabelece o currículo pleno do Curso de Pedagogia, do Setor de Educação, UFPR.

Ementas de disciplinas obrigatórias do Curso de Pedagogia. 


\section{SETOR DE EDUCAÇÃO \\ COORDENAÇÃO DO CURSO DE PEDAGOGIA}

\section{RESOLUÇÃO N.・02/85}

Estabelece o Currículo Pleno do Curso de Pedagogia, do Setor de Educação.

O CONSELHO DE ENSINO E PESQUISA, órgão normativo, consultivo e deliberativo da admiinstração superior, no uso de suas atribuições conferidas pelo artigo 21 do Estatuto da Universidade Federal do Paraná,

\section{RESOLVE:}

Artigo $10^{\circ}$ - As matérias e seu desdobramento em disciplinas e práticas profissionais que constituem o Currículo Pleno do Curso de Pedagogia, nas suas habilitações: Magistério das Disciplinas Pedagógicas do Ensino de 2. Grau, Administração Escolar, Orientação Educacional e Supervisão Escolar, são as seguintes:

\section{MATÉRIAS}

\section{DESDOBRAMENTO}

\section{A - FORMAÇÃo GERAL}

1 - Estudo de Problemas Brasilei- 1.1 - Estudos de Problemas Brasileiros

2 - Educação Física

2.1 - Prática Desportiva

2.2 - Desporto de Livre Escolha

B - FORMAÇÃO BÁSICA

1 - Sociologia

2 - Psicologia da Educação

3 - História da Educação

4 - Sociologia da Educação

5 - Filosofia da Educação
1.1 - Sociologia

2.1 - Psicologia da Educação B

2.2 - Psicologia da Educação C

3.1 - História da Educação

3.2 - História e Filosofia da Educação Brasileira

4.1 - Sociologia da Educação

5.1 - Filosofia da Educação 

6 - Estrutura e Funcionamento do
Ensino
6.1 - Estrutura e Funcionamento do Ensino de 1. Grau

6.2 - Estrutura e Funcionamento do Ensino de 2. $\mathrm{Grau}$

\section{C - FORMAÇÃO PROFISSIONAL}
1 - Metodologia do Ensino
1.1 - Metodologia do Ensino de 1.. e 2. Graus
2 - Estatística Aplicada à Educa- ção
3 - Práitica de Ensino da Escola de
3 - Prática de
3.1 - Prática de Ensino de $1 .^{\circ}$
2.1 - Estatística Educacional
4 - Currículos e Programas de Ensino e 2. Graus
5 - Didática
4.1 - Currículos e Programas de Ensino de $1 .^{\circ}$ e $2 .^{\circ}$ Graus
5.1 - Didática

\section{D - FORMAÇÃO PROFISSIONAL ESPECÍFICA PARA A HABILITAÇÃO EM ADMINISTRAÇÃO ESCOLAR}

1 - Estágio Supervisionado em Administração Escolar

2 - Administração Escolar

3 - Princípios e Métodos de Administração Escolar

4 - Avaliação da Escola
1.1 - Estágio Supervisionado em Administração Escolar

2.1 - Administração da Escola de 1. ${ }^{\circ}$ Grau

2.2 - Administração da Escola de 2. Grau

2.3 - Administração do Sistema Educacional Brasileiro

3.1 - Princípios e Métodos de Administração Escolar

4.1 - Avaliação da Escola

\section{E - FORMAÇÃO PROFISSIONAL ESPECíFICA PARA A HABILITAÇÃO EM ORIENTAÇÃO EDUCACIONAL}
1 - Princípios e Métodos de Orientação Escolar
1.1 - Princípios e Métodos de Orientação Educacional
2 - Orientação Educacional
2.1 - Orientação Educacional na Escola de 1: e 2. Graus
2.2 - Orientação Educacional na Escola não Formal
3 - Orientação Vocacional
3.1 - Orientação Vocacional
4 - Medidas Educacionais
4.1 - Medidas Educacionais 
5 - Estágio Supervisionado em
Orientação Educacional
5.1 - Estágio Supervisionado em Orientação Educacional

\section{F - FORMAÇÃO PROFISSIONAL ESPECÍFICA PARA A HABILITAÇÃO EM SUPERVISÃO ESCOLAR}
1 - Supervisão Escolar
1.1 - Supervisão da Escola de 1. Grau
1.2 - Supervisão da Escola de 2. Grau
1.3 - Supervisão e os Problemas do Currículo
2 - Princípios e Métodos de Supervisão Escolar
2.1 - F'rincípios e Métodos de Supervisão Escolar
3 - Avaliação da Escola
3.1 - Avaliação da Escola
4 - Estágio Supervisionado em Supervisão Escolar
4.1 - Estágio Supervisionado em Supervisão Escolar

\section{G - FORMAÇÃO COMPLEMENTAR}

\section{I - Obrigatórias}

1 - Biologia Educacional

2 - Educação Comparada

3 - Legislação do Ensino

4 - Métodos e Técnicas de Pesquisa Educacional

5 - Concepções e Métodos de Alfabetização

6 - Planejamento Educacional

7 - Aspectos Econômicos e Folíticos da Educação
1.1 - Biologia Educacional

2.1 - Educação Comparada

3.1 - Legislação do Ensino e Ética Profissional

4.1 - Métodos e Técnicas de Pesquisa Educacional $A$

5.1 - Concepções e Métodos de Alfabetização

6.1 - Planejamento Educacional

7.1 - Aspectos Econômicos e Políticos da Educação

\section{II - Disciplinas Optativas}

1 - Introdução à Antropologia

2 - Homem, Cultura e Sociedade

3 - Antropologia Brasileira

4 - Antropologia Cultural A

5 - Psicologia Social A

6 - Psicologia Social B

7 - Métodos Estatísticos e Teoria das Medidas

8 - Psicologia Escolar e Problemas de Aprendizagem 
9 - Psicologia Aplicada à Administração A

10 - Cultura F'opular e de Massa no Brasil

11 - História da Arte Brasileira

12 - Arte Popular no Brasil A

13 - Política Educacional

14 - Problemas de Aprendizagem Escolar

15 - Sociologia da Escola

16 - História da Educação Pré-Escolar

17 - Psicologia da Educação de Adultos

18 - Tendências da Psicologia da Educação Contemporânea

19 - História da Educação das Américas

20 - Estrutura e Funcionamento do Ensino do 3. Grau

21 - Economia da Educação

22 - Introdução ao Planejamento Educacional

23 - Introdução ao Estudo do Currículo

24 - Currículos e Programas do Ensino de 1.० e 2. Graus

25 - Orientação Educacional no Currículo

26 - Planejamento Curricular do Ensino Especial

27 - Educação no Meio Rural

28 - Educação Permanente

29 - Educação de Adultos e sua Organização

30 - Desenvolvimento Interpessoal na Educação

31 - Educação Popular

32 - Educação e Trabalho

33 - Alternativas de Gestão na Escola Brasileira

34 - Estrutura e Funcionamento do Ensino Superior

35 - Pesquisa Bibliográfica em Educação

36 - Orientação Bibliográfica $A$

37 - Orientação Bibliográfica B

38 - Bibliotecas Infantis e Escolares

39 - Problemas Fundamentais de Filosofia A

40 - Introdução à Ética $\mathrm{A}$

41 - Introdução à Filosofia $A$

42 - Manifestações Literárias no Paraná

43 - Fundamentos de Educação Física

44 - Lazer e Recreação A

45 - Lazer e Recreação B

46 - Higiene e Saúde Escolar

47 - Introdução à Educação Especial

48 - Introdução à Psicologia

49 - Metodologia do Ensino de Comunicação e Expressão no 1.: Grau

50 - Metodologia do Ensino de Estudos Sociais no $1 .^{\circ}$ Grau 
51 - Metodologia do Ensino de Ciências no 1. Grau

52 - Metodologia do Ensino de Psicologia

53 - Metodologia do Ensino na Pré-Escola

54 - Tecnologia da Educação I

55 - Tecnologia da Educação II

Art. $2^{\circ}-\mathrm{O}$ acesso ao Curso de Pedagogia nas suas habilitações, de que trata esta Resolução, será feito mediante Concurso Vestibular, ocasião em que o candidato fará ingresso na habilitação "Magistério das Disciplinas Pedagógicas do Ensino de 2.॰ Grau".

Parágrafo único - Ao ingressar na modalidade referida no artigo $2 .{ }^{\circ}$, o aluno de Pedagogia obrigar-se-á a cursar mais uma habilitação específica, a saber: "Administração Escolar" ou "Orientação Educacional" ou "Supervisão Escolar".

Art. $3 .^{\circ}-\mathrm{O}$ aluno do Curso de Pedagogia deverá comprovar experiência de magistério, docente ou equivalente, quando da obtenção do diploma, em um mínimo de 6 (seis) meses para Administração Escolar e Supervisão Escolar e de 1 (um) ano para Orientação Educacional, de acordo com a determinação superior pertinente.

Art. $4 .^{\circ}-\mathrm{A}$ integralização do currículo pleno do Curso de Pedagogia, nas habilitações objeto desta Resolução, será feita em um mínimo de 2.580 (duas mil, quinhentas e oitenta) horas de atividades escolares, não podendo a graduação ocorrer em menos de quatro anos e em mais de sete anos.

$\S 1 .^{\circ}-\mathrm{A}$ integralização das 2.580 horas para as habilitações em Administração Escolar, Orientação Educacional e Supervisão Escolar, será feita com o mínimo de 60 (sessenta) horas de disciplinas optativas, que o aluno poderá escolher dentre as relacionadas no artigo $1 .^{\circ}$, desde que não pertençam ao rol das disciplinas obrigatórias da habilitação escolhida.

$\S 2 .^{\circ}$ - As cargas horárias mínima e máxima de matrícula anual serão, respectivamente, de 13 (treze) e de 26 (vinte e seis) horas semanais, de atividades escolares. 
Art. 5. - Complementam o Currículo do Curso de Pedagogia, em todas as suas habilitações, as disciplinas de Educação Física, totalizando 90 (noventa) horas, e a disciplina de Estudo de Problemas Brasileiros num total de 60 (sessenta) horas.

Art. $6 .^{\circ}$ - Ao diplomado em Pedagogia fica facultado o direito de obter uma outra habilitação específica entre as tratadas nesta Resolução, desde que haja vagas no curso, obedecidos os critérios de ocupação estabelecidos pelo Conselho de Ensino e Pesquisa.

Art. 7. $-\mathrm{O}$ aluno do Curso de Pedagogia ou em complementação de estudos, que estiver cursando o primeiro semestre em 1985 (ano), estará sujeito a esta Resolução.

Parágrafo único - Cabe ao Colegiado do Curso autorizar ou ditar normas complementares de ajustamento à adequação legal.

Art. 8. - Esta Resolução entra em vigor no ano letivo de 1985, revogando-se as disposições em contrário.

Sala das Sessões, em 11 de janeiro de 1985.

ROBERTO LINHARES DA COSTA

Presidente em exercício. 


\section{SETOR DE EDUCAÇÃO \\ COORDENAÇÃO DO CURSO DE PEDAGOGIA \\ CURRículo do CURSO DE PEDAGOGIA \\ TRONCO COMUM}

\section{ANO}

\section{Cód. DISCIPLINAS}

HC402 Sociologia

Cl421 Estatística Educacional

ET402 Psicologia da Educação B

ET410 História da Educação

ET406 Filosofia da Educação

EP408 Estrutura e Funcionamento do

Ensino de 1. ${ }^{\circ}$ Grau A
ET405 Biologia Educacional

Carga Pré-

horária Requisitos

90

60

90

90

120

120

90

660

\section{ANO}

ET416 Sociologia da Educação

EM425 Didática B

EM407 Métodos e Técnicas de Pesquisa

$\mathrm{HC} 402$

90

ET402

EP409 Estrutura e Funcionamento do Educacional A

$$
\text { Ensino de 2. Grau }
$$

EP407 Currículos e Programas do

$$
\text { Ensino de } 1 .^{\circ} \text { e } 2 .^{\circ} \text { Graus }
$$

ET411 História e Filosofia da Educação

$$
\text { Brasileira }
$$

ET403 Psicologia da Educação C

EP406 Legislação do Ensino e Ética

$$
\text { Profissional }
$$




\section{PARTE ESPECÍFICA \\ HABILITAÇÃO: SUPERVISÃO ESCOLAR}

3. ANO

Cód. DISCIPLINAS

Carga Pré-

horária Requisitos

EP415 Princípios e Métodos de

Supervisão Escolar $\quad 120$

EP402 Avaliação da Escola 60

EP416 Supervisão e os Problemas do

Currículo

EM427 Metodologia do Ensino de

1. e 2. Graus

120 EM425

EM423 Concepções e Métodos de

Alfabetização $\quad 60$

EM426 Prática de Ensino de $1 .^{\circ}$ e $2 .^{\circ}$ Graus 180

EM425

Optativas $(2 \times 30)$

60

660

\section{ANO}

EP403 Educação Comparada

EP404 Aspectos Econômicos e Políticos da Educação

EP405 Planejamento Educacional

EP417 Supervisão da Escola de 1. Grau

60

EP418 Supervisão da Escola de 2. Grau

60

60

90

EP419 Estágio Supervisionado em

Supervisão Escolar

EP415

600

Estudo de Problemas Brasileiros... 60 


\section{PARTE ESPECÍFICA \\ HABILITAÇÃO: ADMINISTRAÇÃO ESCOLAR}

\section{ANO}

\section{Cód. DISCIPLINAS}

EM427 Metodologia do Ensino de

$$
\text { 1. }{ }^{\circ} \text { e } 2 .^{\circ} \text { Graus }
$$

EM423 Concepções e Métodos de

$$
\text { Alfabetização }
$$

EM426 Prática de Ensino de $1 .^{\circ}$ e $2 .^{\circ}$ Graus EP410 Princípios e Métodos de Administração Escolar

EP402 Avaliação da Escola

EP411 Administração do Sistema

Educacional Brasileiro Optativas (2 x 30$)$

\section{Carga Pré- \\ horária Requisitos}

$120 \quad$ EM425

180

EM425

660

\section{ANO}

EP403 Educação Comparada

EP404 Aspectos Econômicos e Políticos

$$
\text { da Educação }
$$

EP405 Planejamento Educacional

EP412 Administração da Escola de 1. Grau

EP413 Administração da Escola de $2 .^{\circ}$ Grau EP414 Estágio Supervisionado em

Estudo de Problemas Brasileiros.. 


\section{PARTE ESPECÍFICA \\ HABILITAÇÃO: ORIENTAÇÃO EDUCACIONAL}

\section{3..$^{\circ}$ ANO}

Cód. DISCIPLINAS

EP420 Princípios e Métodos de

Orientação Educacional

EP421 Orientação Vocacional

EP422 Medidas Educacionais

EM427 Metodologia do Ensino de

$$
1 .^{\circ} \text { e } 2 .^{\circ} \text { Graus }
$$

EM423 Concepções e Métodos de

$$
\text { Alfabetização }
$$

EM426 Prática de Ensino de $1 .^{\circ}$ e $2 .^{\circ}$ Graus
Carga Pré-

horária Requisitos

120

90

90

$120 \quad$ EM425

60

180

EM425

660

\section{4. ${ }^{\circ}$ ANO}

EP423 Orientação Educacional no Ensino de $1 .^{\circ}$ e $2 .^{\circ}$ Graus

60

EP424 Orientação Educacional na

Educação não Formal

EP425 Estágio Supervisionado em

Orientação Educacional

EP403 Educação Comparada

EP404 Aspectos Econômicos e Políticos da Educação

60

240

60

60

EP405 Planejamento Educacional

60

Optativas $(2 \times 30)$

60

600

Estudo de Problemas Brasileiros... 60 


\section{EMENTA DE DISCIPLINAS OBRIGATÓRIAS DO CURSO DE PEDAGOGIA E SUAS HABILITAÇÕES}

Não foram incluídas aqui as emendas das disciplinas optativas e das disciplinas de formação geral.

\section{ET405 - BIOLOGIA EDUCACIONAL}

Contribuição da biologia no processo educativo. Aspectos biológicos do crescimento e desenvolvimento.

3003/6; 75 e 77 .

\section{HC402 - SOCIOLOGIA}

Organização social (configuração). Sociologia (definição e métodos). Unidade estrutural da sociedade (elementos formadores, integradores e funcionais). Continuidade e mudança social (controle social, teorias de mudança social, transformações sociais). Instituições sociais: funções e tipos. Sistemas sociais. Instituições e sociedade. Instituições e processos sociais. A transformação social e a obsolescência. 2002/4; 86 e 98.

\section{CI421 - ESTATÍSTICA EDUCACIONAL}

Introdução à Estatística. Fases de um trabalho estatístico. Representação tabular. Representação gráfica. Números relativos significativos no planejamento educacional. Distribuição de freqüência. Caracterização quanto a uma variável: medidas de tendência central, posição, variabilidade, assimetria. Curva normal. Amostragem. Hipóteses estatísticas. Coeficientes de correlação. Validade e fidedignidade de instrumentos. Relação de índices educacionais com outros fatores. $3003 / 6 ; 75$ e 77 .

\section{ET402 - PSICOLOGIA DA EDUCAÇÃO B}

Conceito, objeto, métodos e importância da Psicologia da Educação. Desenvolvimento cognitivo da infância à vida adulta 
e suas implicações na educação escolar. Socialização e afetividade no contínuo do processo de desenvolvimento. Perturbações da personalidade na infância, adolescência e idade adulta. A marginalização cultural e suas implicações psicopedagógicas. $3003 / 6 ; 75$ e 77 .

\section{ET410 - HISTÓRIA DA EDUCAÇÃO}

Quadros conceituais. Métodos e técnicas operacionais. O tradicionalismo pedagógico. O mundo clássico e a educação. A pedagogia e cristianismo. $\mathrm{O}$ humanismo pedagógico. $\mathrm{O}$ realismo pedagógico. Ideais pedagógicos da enciclopédia. A educação naturalista. Sistematização científica da pedagogia. A pedagogia idealista, sociológica e evolucionista. O movimento da escola nova.

$4004 / 8 ; 75$ e 77 .

\section{ET406 - FILOSOFIA DA EDUCAÇÃO}

As diversas concepções da educação. Conceituação de Filosofia da Educação. Os fins da educação. O professor e sua filosofia. As grandes correntes da Filosofia da Educação. A escola brasileira e sua filosofia. A filosofia da Lei de Diretrizes e Bases da Educação e da Lei 5692. O direito à educação. A igualdade de oportunidades educacionais. Educação e mudança. Educação, ciência e tecnologia. Educação e economia. Educação, liberdade e democracia.

4004/8; 75 e 77 .

\section{EP408 - ESTRUTURA E FUNCIONAMENTO DO ENSINO DE $10^{\circ}$ GRAU}

O ensino de $1 .^{\circ}$ grau no contexto de educação brasileira. As características do ensino de $10^{\circ}$ grau e sua evolução histórica. Organização e diretrizes do ensino de $11^{\circ}$ grau e da préescola no Brasil e no Paraná. Questões problemáticas no ensino de $10^{\circ}$ grau.

$3003 / 6 ; 75$ e 77 . 


\section{ET416 - SOCIOLOGIA DA EDUCAÇÃO}

Análise sociológica da educação e da escola a partir de problemas da realidade atual e sua relação com as diversas disciplinas científicas. Educação e estrutura social, integração social, funcionamento social e transformação. Cultura e educação. Educação e desenvolvimento econômico e social no Brasil. A escola do meio rural e urbano. Problemas educacionais na América Latina.

4004/8; 75 e 77.

\section{EM425 - DIDÁTICA B}

Profissionalização do professor. Fundamentos teóricos do ensino. Planejamento da ação didática. $O$ professor e a qualidade do ensino. Pensamento da didática moderna. Seminário como técnica de ensino. $3003 / 6 ; 75$ e 77 .

\section{EM407 - MÉTODOS E TÉCNICAS DA PESQUISA EDUCACIONAL A}

A pesquisa pedagógica e suas implicações no processo pedagógico. Dimensões da pesquisa educacional. Bases necessárias para discussão e montagem de um projeto de pesquisa.

2002/4; 75, 77 e 38.

\section{EP409 - ESTRUTURA E FUNCIONAMENTO DO ENSINO DE $2 .^{\circ}$ GRAU}

Determinações sócio-econômicas, políticas e pressupostos teóricos das propostas de ensino de $2 .^{\circ}$ grau na evolução da educação brasileira. Organização, problemática e tendências do ensino de $2 .^{\circ}$ grau no Brasil. Propostas e alternativas para o ensino de $2 .^{\circ}$ grau.

$3003 / 6 ; 75$ e 77 . 


\section{EP407 - CURRÍCULOS E PROGRAMAS NO ENSINO DE 1. E 2.: GRAUS}

Os currículos de $10^{\circ}$ e $2 .^{\circ}$ graus em seus aspectos formais e processuais: seus fundamentos, aspectos gerais de seu desenvolvimento e pressupostos básicos para sua avaliação e aperfeiçoamento. Novas proposições e experiências em currículos e programas no ensino de 1 . e $2 .^{\circ}$ graus. $3003 / 6 ; 75$ e 77.

\section{ET411 - HISTÓRIA E FILOSOFIA DA EDUCAÇÃO BRASILEIRA}

Evolução e interpretação da educação luso-brasileira nas fases colonial, monárquica e republicana, com ênfase sobre a educação brasileira. Concepções filosóficas dominantes nas diversas fases. As reformas pombalinas no ensino e as reformas. educacionais brasileiras, com ênfase sobre as reformas nas últimas décadas. A educação no Paraná.

2002/4; 75 e 77.

\section{ET403 - PSICOLOGIA DA EDUCAÇÃO C}

Concepções teóricas contemporâneas sobre o processo ensino-aprendizagem e suas implicações para a atividade docente. Interação professor-aluno.

$3003 / 6 ; 75$ e 77 .

\section{EP406 - LEGISLAÇÃO DO ENSINO E ÉTICA PROFISSIONAL}

O Direito Educacional Brasileiro. Notas sobre uma Introdução ao Estudo do Direito. As concepções de estado e suas implicações na conceituação de lei. A legislação educacional na concretização do ensino pré-escolar, do ensino de $1 .^{\circ} \mathrm{grau}, 2 .^{\circ}$ grau, $3 .^{\circ}$ grau, da educação especial e do ensino supletivo. Implicações na organização escolar. Ética: aspectos, concepções e conceituação. A ética circunscrita à história e como codificação filosófica. A ética, o saber e o poder. A ética profissional como evento problematizador da realidade e como materialidade circunstanciada.

2002/4; 75 e 77 . 


\section{EP415 - PRINCíPIOS E MÉTODOS DE SUPERVISÃO ESCOLAR}

A realidade educacional brasileira e suas implicações na função supervisora. Concepções de educação e a ação supervisora decorrente. Quadro conceptual da supervisão na realidade brasileira: princípios, objetivos e funções. A metodologia do processo da supervisão. A supervisão como fator de melhoria da qulaidade de ensino.

4004/8; 75 e 77.

\section{EP402 - AVALIAÇÃO DA ESCOLA}

A avaliação do traablho escolar no contexto da educação brasileira: exame dos seus pressupostos. As concepções e teorias de avaliação escolar. O desempenho da escola e os modelos para a sua avaliação. Proposições metodológicas para o acompanhamento da prática escolar.

2002/4; 75 e 77.

\section{EP416 - SUPERVISÃO E OS PROBLEMAS DO CURRÍCULO}

A dinâmica do planejamento curricular. As questões pedagógicas do currículo: os problemas da aprendizagem e do currículo. A avaliação curricular como fator para ativação e desenvolvimento da escola.

2002/4; 75 e 77 .

\section{EM427 - METODOLOGIA DO ENSINO DE $1 .^{\circ}$ E $2 .^{\circ}$ GRAUS}

Alternativas metodológicas no ensino de $10^{\circ}$ e $2 .^{\circ}$ graus e suas implicações no processo de ensino-aprendizagem. Enfoques metodológicos sobre problemas na sala de aula, oriundos de implicações econômico/sociais, histórico/culturais e científico/ tecnológicas na vida das crianças.

4004/8; 75 e 77.

\section{EM423 - CONCEPÇõES E MÉTODOS DE ALFABETIZAÇÃO}

Os fundamentos teóricos da alfabetização: lingüísticos, psicológicos e sociológicos. Variáveis intervenientes na tarefa da 
alfabetização. Procedimentos de alfabetização. A formação do professor alfabetizador.

2002/4; 75 e 77.

\section{EM426 - PRÁTICA DE ENSINO DE 1. E 2. GRAUS}

Realidade escolar de $1 .^{\circ}$ e $2 .^{\circ}$ graus. Escolas de $1 .^{\circ}$ e $2 .^{\circ}$ graus. A sala de aula como laboratório de aprendizagem. Estratégias metodológicas para $1 .^{\circ}$ e $2 .^{\circ}$ graus.

3036/8; 75 e 77.

\section{EP403 - EDUCAÇÃO COMPARADA}

Espaço e tempo da Educação Comparada. Estrutura teórica da Educação Comparada. A comparação a nível internacional, intranacional e transnacional. Problemas e tendências educacionais atuais no mundo.

2002/4; 75 e 77.

\section{EP404 - ASPECTOS ECONÔMICOS E POLÍTICOS DA EDUCAÇÃO}

A educação no contexto do desenvolvimento do processo produtivo contemporâneo e da organização dos estados nacionais. A evolução do pensamento na economia política e suas implicações na organização do trabalho escolar. O mercado de trabalho e a profissionalização do ensino. A "questão econômica e política" na atual estrutura do ensino brasileiro. 2002/4; 75 e 77.

\section{EP405 - PLANEJAMENTO EDUCACIONAL}

Conceitos, características e níveis do Planejamento Educacional. Aspectos sócio-econômicos e culturais da educação. Determinação das necessidades educacionais. Diagnóstico e programação educacional. Formulação do plano de educação. Elaboração, controle e avaliação de projetos educacionais. 2002/4; 75 e 77. 


\section{EP417 - SUPERVISÃO DA ESCOLA DE $10^{\circ}$ GRAU}

Caracterização dos aspectos pedagógicos e administrativos referentes à supervisão a nível de sistema e de organização escolar no $1 .^{\circ}$ grau. Análise da ação supervisora em diferentes tipos de escolas e modalidades de ensino. $3003 / 6 ; 75$ e 77 .

\section{EP418 - SUPERVISÃO DA ESCOLA DE 2. GRAU}

Caracterização dos aspectos pedagógicos e administrativos referentes à supervisão a nível de sistema e de organização escolar no $2 .^{\circ}$ grau. Análise da ação supervisora em diferentes tipos de escola e modalidades de ensino. $3003 / 6 ; 75$ e 77 .

\section{EP419 - ESTÁGIO SUPERVISIONADO EM SUPERVISÃO ESCOLAR}

Caracterização dos aspectos pedagógicos e administrativos referentes à supervisão a nível de sistema e de organização escolar no $1 .^{\circ}$ e $2 .^{\circ}$ graus. Análise da ação supervisora em diferentes tipos de escola e modalidades de ensino. Proposta, execução e avaliação da ação supervisora no $1 .^{\circ}$ e $2 .^{\circ}$ graus. 0268/6; 75 e 77.

\section{EP410 - PRINCíPIOS E MÉTODOS DE ADMINISTRAÇÃO ESCOLAR}

As origens da gerência e da divisão do trabalho e suas implicações na organização escolar. A abordagem teórica da admi nistração no processo histórico. Administração empresarial e escolar. Os problemas teórico-práticos na administração da escola brasileira. Conceitos explicativos do processo administrativo na escola brasileira.

4004/8; 75 e 77. 


\section{EP411 - ADMINISTRAÇÃO DO SISTEMA EDUCACIONAL BRASILEIRO}

O modelo de administração do sistema escolar brasileiro e a realidade: a política administrativa, as formas de planejamento e o processo decisório. A gestão financeira da educação no Brasil: a origem dos recursos e as formas de distribuição. A divisão de tarefas entre as esferas federal, estadual e municipal e as formas específicas de estruturação; centralização e descentralização. Os programas especiais e suas formas de gestão (merenda escolar, material didático, livro didático, serviços de assistência ao escolar, etc.). As questões relativas à administração do pessoal técnico e docente; as políticas salarial e de qualificação; os direitos trabalhistas. A administração da rede física; recursos e responsabilidades.

2002/4; 75 e 77.

\section{EP412 - ADMINISTRAÇÃO DA ESCOLA DE 1. GRAU}

Análise da teoria da administração educacional: suas pressuposições básicas. A teoria da administração educacional no Brasil. Os problemas da escola de $1 .^{\circ}$ grau e sua administração. Definição do campo de atuação da administração educacional. 3003/8; 75 e 77.

\section{EP413 - ADMINISTRAÇÃO DA ESCOLA DE 2. GRAU}

A política da educação de $22^{\circ}$ grau. Os problemas da escola de 2. grau e a administração escolar. Análise das perspectivas de mudança da organização escolar de $2 .^{\circ}$ grau em face das características do contexto brasileiro. $\mathrm{O}$ processo e as propostas de trabalho administrativo no quadro da educação brasileira. $3003 / 6 ; 75$ e 77 .

\section{EP414 - ESTÁGIO SUPERVISIONADO EM ADMINISTRAÇÃO ESCOLAR}

Observação e caracterização do contexto administrativo-pedagógico de unidades escolares tendo em vista suas relações com o sistema educacional brasileiro nos seus vários níveis. 
Análise crítica das situações problemáticas encontradas na realidade escolar: formulação e aplicação de proposições alternativas nessa realidade.

$0268 / 6 ; 75$ e 77 .

\section{EP420 - PRINCíPIOS E MÉTODOS DE ORIENTAÇÃO EDUCACIONAL}

A educação e o significado da orientação educacional. Pressupostos legais, históricos, filosóficos, sociológicos e psicológicos da orientação educacional, na realidade brasileira. Funções específicas e integrativas da orientação educacional. A orientação educacional no processo educativo; linhas de ação de orientação educacional. Operacionalização da orientação educacional de acordo com as perspectivas da realidade escolar. $4004 / 8 ; 75$ e 77 .

\section{EP421 - ORIENTAÇÃO VOCACIONAL}

A orientação vocacional e o trabalho no contexto sócio-econômico-político brasileiro e implicações para a orientação vocacional no âmbito escolar. Relações entre trabalho, educação e lazer em suas dimensões sócio-econômica, cultural e psicológica. A informação profissional na realidade brasileira. Teorias sobre escolha e desenvolvimento vocacional e implicações para a prática escolar. Ativação do desenvolvimento vocacional. Programas e projetos de orientação vocacional no âmbito escolar e para-escolar.

$3003 / 6 ; 75$ e 77 .

\section{EP422 - MEDIDAS EDUCACIONAIS}

As dimensões individual, social e pedagógica do processo de medida e avaliação. O processo de mensuração no acompanhamento psicossociopedagógico. Métodos e técnicas de caracterização das condições sociais, familiares e escolares relacionadas ao processo educacional. Análise, elaboração e aplicação de instrumentos de medidas. Esțudo de programas de avaliação. $3003 / 6 ; 75$ e 77 . 


\section{EP423 - ORIENTAÇÃO EDUCACIONAL NO ENSINO DE 1.' E 2.: GRAUS}

O papel da orientação educacional no ensino de $1 .^{\circ}$ e $2 .^{\circ}$ graus regular e supletivo. Caracterização da abordagem da orientação educacional em relação aos problemas educacionais de cada um desses contextos de escolaridade. Organização, planejamento e avaliação de propostas e projetos de orientação educacional para esses contextos.

2002/4; 75 e 77 .

\section{EP424 - ORIENTAÇÃO EDUCACIONAL NA EDUCAÇÃO NÃO FORMAL}

Relações entre desenvolvimento humano, contexto vital e necessidades de orientação. $O$ papel da orientação educacional em instituições públicas e organizações ou programas que visem ao desenvolvimento do homem. Utilização de métodos e técnicas de orientação educacional para elaboração de planos de ação junto a essas instituições, organizações e programas. 2002/4; 75 e 77.

\section{EP425 - ESTÁGIO SUPERVISIONADO EM ORIENTAÇÃO EDUCACIONAL}

Observação participativa no contexto real do trabalho do orientador educacional como especialista da educação. Elaboração, aplicação e avaliação de estratégias de ação comprometidas com transformação e mudanças.

0268/ 75 e 77. 